Original Article

Bal G Karmacharya, MS, FCPS

Department of Neurosurgery

Manipal Teaching Hospital, MCOMS

Pokhara

Brijesh Sathian, PhD

Department of Community Medicine

Manipal Teaching Hospital, MCOMS

Pokhara

Address for Correspondence:

Bal G Karmacharya, MS, FCPS

Consultant Neurosurgeon

Manipal Teaching Hospital, Pokhara

Email: dr.balgopal@hotmail.com

Received, 15 October, 2015

Accepted, 26 October, 2015

$\mathrm{E}$ arthquakes are one of most devastating natural disasters. It occurs abruptly without any warnings. Devastating earthquake occurred in Nepal on $25^{\text {th }}$ April 2015 at 11:56 AM. It measured 7.8 Richter scale. ${ }^{10}$ Epicenter was on the east of Lamjung and hypocenter was at around only 15 kilometers depth. The epicenter was around 80 kilometers northwest of the capital Kathmandu. It killed more than 8964 and injured more than 21952 people $^{8}$ as it flattened mountain villages and destroyed buildings in the Himalayan region.

The injuries sustained during earthquakes are diverse. However crush injuries are the most common because of the collapse of buildings. Victims may sustain injuries due to falls during escape also. They usually sustain combination of injuries, including head and neck, chest, abdomen and extremities. A few patients may have isolated injuries.

Manipal Teaching Hospital is the only hospital in the western region to cater to neurosurgical patients. Patients were either directly flown in from the incident site or referred from other health care facilities after the initial treatment. In the western region, most affected areas were Barpak and Larpak in Gorkha district. Few patients came from Kaski, Tanahu, Lamjung and Parbat. Patients were
Nepal Journal of Neuroscience 12:63-66, 2015

\section{Study of Traumatic Brain Injury Due To Recent Earthquake in Manipal Teaching Hospital}

The objective of this study was to review the demographics, causes injury, severity, treatment and outcome of traumatic brain injuries in victims of the April 2015 earthquake who were admitted in Manipal Teaching Hospital, Pokhara. A total of 37 patients was admitted under Neurosurgery Services. Collapse of buildings was the commonest cause of head injury. The majority of them had mild head injury. Associated injuries to other parts of the body were present in $40.54 \%$ patients.

Key Words: earthquake, extradural hematoma, head injury

brought to hospital on the same day for several days after the earthquake.

The objectives of the study were to find out data regarding the demographic status, type of craniocerebral trauma, treatment offered and outcome of head injuries.

\section{Material And Methods}

It was a hospital based observational study of all cases of head injury victims admitted in Manipal Teaching Hospital. Prospectively kept and filled pro forma were analyzed for demographic data regarding age and sex of the patients, time since the injury to hospital admission, cause of head injury, severity of traumatic brain injury based on the Glasgow Coma Score, ${ }^{9}$ findings on CT scan of the brain, treatment provided and outcome based on the Glasgow Outcome score. ${ }^{5}$ Outcome was measured at discharge. Ethical clearance was taken from an Institutional Review Board.

\section{Sample size calculation}

In a pilot study done prior to the original study with 10 patients showed Collapse of buildings was the commonest cause of injury in 7 out of 10 patients (70\%). With 15\% absolute precision and 95\% Confidence interval required sample size was 35 . 


\section{Karmacharya et al}

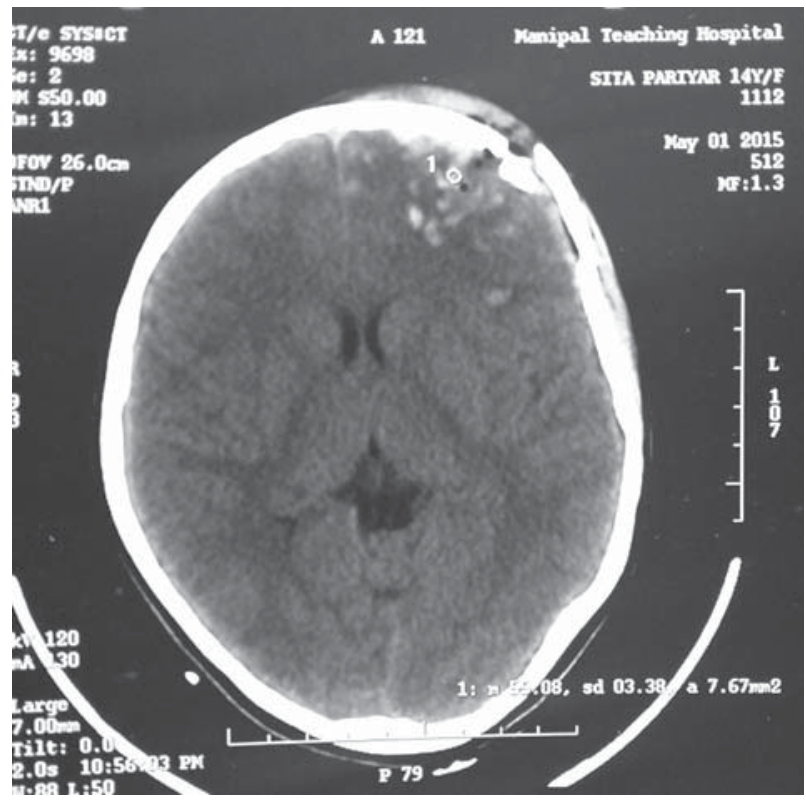

Figure 1: CT scan showing left frontal compound fracture and contusions

\section{Results}

There were 37 patients in total who were admitted for craniocerebral injuries. Among them, twenty six patients were brought from Gorkha district, the most affected district in this region.

\section{Age and Sex of Patients}

There were 18 males (48.65\%) and 19 females (51.35\%) patients. There were patients of all age groups. The age distribution of patients is shown in fig 1 . Mean age of patients was 34.25 years (range 2-85 yrs).

\section{Cause of injuries}

Collapse of buildings was the commonest cause of injury in 24 patients (64.86\%), followed by a fall during escape in 9 patients (24.32\%). Two patients (5.41\%) had injuries related to motor vehicle accidents and two patients (5.41\%) sustained an injury due to fall from the tree during the shaking.

\section{Severity of head injuries}

Twenty nine patients (78.38\%) had mild head injuries, 6 patients (16.21\%) had moderate head injuries and 2 patients (5.41\%) had severe head injuries.

\section{CT scan findings}

CT scan was normal in twenty patients (54.05\%). There were skull fractures in 10 patients (27.02\%), (Figure 1) intracranial hematomas in 8 patients (21.62\%)

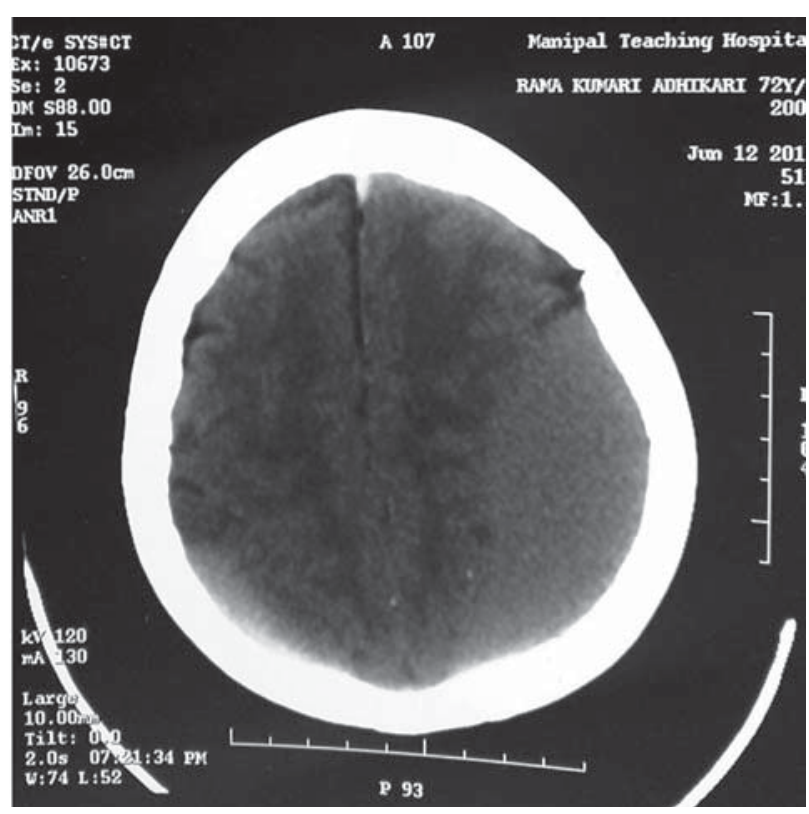

Figure 2: CT scan showing left sided chronic subdral hematoma

and pneumocephalus in 3 patients (8.15\%). Extradural hematoma was in 2 patients, subdural hematomas in 3 patients (Figure 2) and contusions in 3 patients.

\section{Associated injuries}

Fifteen patients (40.54\%) had associated injuries to other parts of the body. Six patients had spinal injuries, 4 had rib fractures, 3 patients had facial injuries and 2 had abdominal visceral injuries.

\section{Treatments offered}

Eighteen patients (48.65\%) underwent surgery, which included debridement and suturing of large scalp laceration in 3, spinal fixation in six patients, craniotomy and evacuation of hematomas in 6 patients and elevation of depressed fractures in 3. All associated injuries were treated non-operatively.

\section{Time since the injury to hospital admission}

Only two patients were brought on the day of the quake. On the following day, 8 patients were brought. The majority of patients, 25 patients were brought on the $3^{\text {rd }}$ day. And 2 patients were brought several days later.

\section{Outcome}

Mean hospital stay was 11 days (range $4-36$ days). The outcome was assessed at the time of discharge. At the time of discharge 30 patients (81.1\%) had a good recovery, 2 patients (5.4\%) had moderate disability, 3 patients (8.12\%) had severe disability and one patient died. During 
the hospital course, one 73 years old man with multiple intracerebral contusions died of pneumonia.

\section{Discussions}

Earthquake is the most important fatal natural disaster. ${ }^{3}$ It causes numerous deaths in crowded city regions and also in areas with buildings with weak structural quality. Deaths may occur on the site in $2 / 3$ of the victims and $1 / 3$ after the evacuation in hospitals. ${ }^{11}$ Injuries resulting deaths are either multisystem or usually penetrating wounds. Deaths are more common in injured children and elderly. ${ }^{7}$ Multisystem injuries are important dimensions of injury following earthquake.

In earthquakes, head injuries range from 3.2\% to $61 \%$ and incidence of reported spinal trauma ranges between 4.9\% and 31.1\%. ${ }^{8}$ Head injuries have been extensively studied in previous earthquakes in Taiwan, ${ }^{7}$ Pakistan, ${ }^{2}$ China, ${ }^{6,12}$ and Turkey. ${ }^{1}$

In the study done by Bhatti SH et $\mathrm{al}^{9}$ in 2005 October earthquake in Pakistan, children lees than 10 years constituted $41 \%$ and more than 55 years constituted $36 \%$ of all patients. Mild head injury occurred in 55\%, moderate head injury in 35\%, severe head injuries in 10\% of patients. Conservative treatment was carried out in $48.7 \%$, minor surgery in $17 \%$ and major surgery in $34.3 \%$ of the patients. Mortality at 6 months was 3.3\%.

In the study done by Lu Jia et al ${ }^{10}$ in Sichuan earthquake in 2008 in China, among all head injured patients, scalp injuries was present in 65\%, skull fractures in $28 \%$ and intracranial hematomas in $10 \%$. Mild, moderate and severe head injuries occurred in $71 \%, 17 \%$ and $12 \%$ of head injured patients respectively. First day 18\%, second day $35 \%$, third day $29 \%$, fourth day $18 \%$

In the study done by Yang $\mathrm{CH}$ et $\mathrm{al}^{11}$ in 2008 Wenchuan earthquake in China, male female ratio of patients was 1.7:1. Mild, moderate and severe head injuries occurred in 80, 12 and 8\% of all head injuries. Collapse of building was the commonest cause of head injuries in this study. Open head injuries accounted for 60.8\%. Operative procedures were carried out in 56\%. Good recovery was achieved in $82.43 \%$ patients, moderate disability in $8.27 \%$, severe disability in $5.55 \%$, coma in $2.26 \%$ and death in $1.5 \%$. In the study of neurosurgical injuries done by Aycan A et al ${ }^{12}$ in 2011 Van earthquake in Turkey: head injuries were isolated in $90.9 \%$ and were associated with spinal injuries in $9.1 \%$.

The findings of our study were similar to other studies done by Bhatti SH and Wang $\mathrm{CH}$.
Human beings do not have the ability to prevent earthquakes. The delayed arrival of rescue and medical units along with severe infrastructure problems strain the emergency medical services and hospital based facilities. It will have a major impact on the chances of survival of seriously injured and trapped. However, we can take measures to minimize injuries and damage by using strict building codes and constructing infrastructures in areas of less risk.

\section{Conclusions}

In this study most of head injuries sustained by the victims were mild head injuries. Most were isolated injuries. The majority was rescued later as the areas were inaccessible. The majority had good outcomes

\section{References}

1. AycanA, Yener U, Aycan N, Gönüllü E, Dursun R, Gönüllü H. Neurosurgical Injuries Caused by the 2011 Van Earthquake: The Experience at the Van Regional Training and Research Hospital. J Emerg Med 49: 464-470, 2015

2. Bhatti SH, Ahmed I, Qureshi NA, Akram M, Khan J. Head trauma due to earthquake October, 2005 experience of 300 cases at the Combined Military Hospital Rawalpindi. J Coll Physicians Surg Pak 18: 22-26, 2008

3. Dabas RS, Das Rupesh M, Sharma K, Pillai KGM. Ionospheric pre-cursors observed over low latitudes during some of the recent major earthquakes. J Atmos Sol Terr Phys 69:1813-1824, 2007

4. Jacquet GA, Hansoti B, Vu A, Bayram JD. Earthquake-Related Injuries in the Pediatric Population: A Systematic Review. PLOS Currents Disasters, 2013 Nov 27. Edition 1. doi: 10.1371/ currents.dis.6d3efba2712560727c0a551f4febac16.

5. Jennett B, Bond M: Assessment of outcome after severe brain damage. Lancet 1: 480-484, 1975

6. Jia L, Li Gp, You C, Li H, Huang Sq, Yang Ch, Xiong $\mathrm{H}$, Zeng $\mathrm{Yj}$. The epidemiology and clinical management of craniocerebral injury caused by the Sichuan earthquake. Neurol India 58: 85-89, 2010

7. Liang NJ, Shih YT, Shih FY, Wu HM, Wang HJ, Shi SF, et al. Disaster epidemiology and medical response in the Chi-Chi earthquake in Taiwan. Ann Emerg Med 38: 549-555, 2001 


\section{Karmacharya et al}

8. Nepal Disaster Risk Reduction Portal. Incident Report of Earthquake 2015. drrportal.gov.np. Retrieved 28 May 2015.

9. Teasdale G, Jennett B. Assessment of coma and impaired consciousness. A practical scale. Lancet 2: 81-84, 1974

10. Wikipedia, the free encyclopedia. April 2015 Nepal earthquake [Internet]. [cited 2015 Dec 16]. Available from: https://en.wikipedia.org/wiki/April_2015_ Nepal_earthquake
11. Yang CH, Li Q, Lan ZG, Liu JG. Epidemiological features of 1281 patients with head injuries arising from the 2008 Wenchuan earthquake. Chin J Traumatol 15: 96-99, 2012

12. Yavuz Hekimoglu, Ipek Esen Melez, Gurol Canturk, Zerrin Erkol, Nergis Canturk, Mustafa Gokhan Dizdar, Deniz Oguzhan Melez, Osman Nuri Guler. Evaluation of the deaths secondary to entrapment under the debris in the Van. Egyptian Journal of Forensic Sciences 3: 44-47, 2013 